\title{
How much is too much alcohol in tuberculosis?
}

To the Editor:

About one-third of the population worldwide have Mycobacterium tuberculosis infections, although $90 \%$ of infected individuals never develop clinical disease $[1,2]$.

The association between alcohol consumption and tuberculosis (TB) is well known $[3,4]$. Individuals who consume alcohol are considered immune-compromised because they have a greater incidence and severity of infectious diseases than abstainers, and are also more susceptible to lung infections, such as TB and pneumonia [4]. In fact, alcohol users are a group at high risk for TB who should be addressed accordingly with targeted preventative interventions $[5,6]$.

In the present study, we tried to determine the threshold of alcohol consumption that increased the risk for active TB in men and women.

Cases and controls were recruited from primary healthcare units in the same geographical region. Pregnant or lactating women, and individuals infected with HIV or other immunosuppressive conditions were excluded. Cases were patients with active pulmonary TB (with or without pleural involvement), aged $>18$ years-old, and diagnosed with TB at outpatient centres in northern Portugal between August 2013 and September 2015. Controls were healthy individuals aged $>18$ years-old with no suspicion of active TB or history of TB in the participant's household within the previous 5 years.

Registered data included daily alcohol consumption over the previous year (including types of beverages and the quantity consumed), age, sex, area of residence, nationality and current occupation/employment status. The clinical data included co-morbidities (diabetes, chronic kidney disease, rheumatological diseases, solid and haematological cancers, lung disease, silicosis, heart and liver conditions and history of TB) and other risk factors for TB infection (drug abuse, imprisonment, homelessness or residence in a community shelter). This project was approved by Portugal's Northern Region Health Administration Ethics Committee, and all participants provided written informed consent.

We performed separate analyses of men and women in the present study given the fact that the impact of ethanol is different in the two sexes [7]. The crude effect of each evaluated variable on TB infection was investigated by simple logistic regression, except for variables associated with very low numbers of $\mathrm{TB}$ infections. Variables that were statistically significant were then included in a multiple binary logistic regression model. The selection of the best model was based on the likelihood-ratio test whenever possible, and otherwise on the Akaike Information Criterion (AIC). The model discriminability was as the area under the receiver operating characteristic curve (AUC). All statistical analyses were performed with $\mathrm{R}$ software (version 2.12.1). The level of significance was set at 0.05 .

We enrolled 289 subjects in this study, 50.5\% of whom were male. The mean \pm sD (range) age was

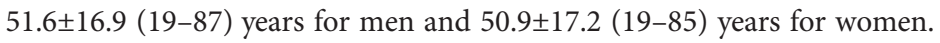

Among men, those with TB were significantly younger (mean \pm SD age $48.1 \pm 17.0$ years versus 56.8 \pm 15.7 years-old) and more likely to be unemployed ( $29 \%$ versus $12 \%$ ). Smokers were significantly more likely to have TB (55\% versus $23 \%$ ). Analysis of alcohol consumption indicated that those who consumed more than $38 \mathrm{~g}$ of ethanol per day had a greater risk of TB than those who did not drink at all. The multiple logistic model indicated that drinking more than $38 \mathrm{~g}$ of ethanol per day, young age and being unemployed were statistically significant risk factors for TB (AUC 0.715). According to the model estimates, any 1-year increase in age decreased the odds for TB by 3.8\% (95\% CI 0.938-0.988),

@ERSpublications

Heavy alcohol intake seems to increase risk of TB in males. New measures for alcohol abuse are needed http://ow.ly/2Esr304cDg4

Cite this article as: Francisco J, Oliveira O, Felgueiras Ó, et al. How much is too much alcohol in tuberculosis? Eur Respir J 2017; 49: 1601468 [https://doi.org/10.1183/13993003.01468-2016]. 
unemployment increased the risk two-fold (95\% CI 0.902-6.247) and daily consumption of more than $38 \mathrm{~g}$ of ethanol per day increased the risk for TB four-fold (95\% CI 1.508-10.738).

Females with TB were also significantly younger than those without TB (mean \pm SD age $40.8 \pm 15.6$ years versus $55.4 \pm 15.9$ years). As with the males, the low prevalence of living in poor conditions precluded analysis of this variable. Smoking was also significantly associated with TB in women (32\% versus $11 \%)$.

The multiple logistic model indicated that young age and smoking were statistically significant risk factors for TB, but there was no significant association between alcohol consumption and TB (table 1, AUC 0.753). Thus, for any 1-year increase in age, the model (table 1) estimated a 5.1\% decrease in the odds for TB (95\% CI 0.947-6.724). The effect of current smoking was very close to being statistically significant ( $\mathrm{p}=0.064$ ), so we left in this variable because it provided a better fit. Current smoking accounted for a 2.5-fold greater risk of TB (95\% CI: 0.925-0.974).

Our results showed that men who were younger, drink more than $38 \mathrm{~g}$ of ethanol per day and were unemployed had an increased risk for $\mathrm{TB}$, and that women who were younger and smokers had an increased risk for TB.

Previous studies showed there might be a dose-response relationship between the amount of alcohol consumption and risk for TB. However, few studies have focused on the threshold amount of alcohol that increases the risk for TB [8]. In the present study, we classified men as non-drinkers, moderate drinkers ( $<38 \mathrm{~g}$ ethanol per day), or heavy drinkers ( $>38 \mathrm{~g}$ ethanol per day). In terms of standard drinks ( 1 standard drink=10 g ethanol), $38 \mathrm{~g}$ of ethanol is equivalent to about 4 drinks per day. A previous systematic review reported similar results [8]. However, we found no significant association between alcohol consumption and TB in females. This may be due to the small percentage of women who consumed alcohol in our study population (21\%). Nonetheless, because of biological differences between men and women, we would expect the threshold ( $\mathrm{g}$ ethanol per day) for increasing the risk of TB would be lower in women than men.

Our analysis indicated that young age increased the risk for TB. This is in line with previous research that showed that TB mostly affects adults in their most productive years [9]. Moreover, the existing literature also cites numerous social factors, such as unemployment, as significant risk factors for TB [10]. This is supported by our results.

The two major limitations of this study are that we only measured alcohol consumption in the previous year and that we relied on self-reported alcohol consumption, which may not reflect actual drinking pattern.

In conclusion, the epidemiologic data and other evidence presented here indicate that heavy alcohol consumption in men is an independent risk factor for TB. Other variables significantly associated with TB were unemployment in men, current smoking in women, and young age in men and women.

There are specific interventions that could be routinely offered to vulnerable TB patients such as heavy drinkers [11-14].

Other policy measures, such as increasing taxation on alcoholic beverages and more stringent control of the availability of alcoholic beverages, could reduce the problems associated with heavy drinking. Studies of preventive and treatment interventions for heavy drinkers should also be encouraged.

João Francisco ${ }^{1}$, Olena Oliveira ${ }^{2}$, Óscar Felgueiras ${ }^{3,4}$, A. Rita Gaio ${ }^{3,4}$ and Raquel Duarte ${ }^{2,5,6}$

${ }^{1}$ Internal Medicine, Centro Hospitalar do Porto, Porto, Portugal. ${ }^{2}$ EPIUnit, Institute of Public health, University of Porto, Porto, Portugal. ${ }^{3}$ Mathematics Dept, Faculty of Sciences of the University of Porto, Porto, Portugal. ${ }^{4}$ Centre of Mathematics of the University of Porto, Porto, Portugal. ${ }^{5}$ Pulmonology Dept, Centro Hospitalar de Vila Nova de Gaia/ Espinho EPE, Vila Nova de Gaia, Portugal. ${ }^{6}$ Dept of Clinical Epidemiology, Predictive Medicine and Public Health, University of Porto Medical School, Porto, Portugal.

Correspondence: João Francisco, Rua alexandre Herculano, No 341, Sala 11, 4000-054, Porto, Portugal. Email: joaop.dinis@gmail.com

Received: June 302016 | Accepted after revision: Aug 302016

Support statement: This work was supported by the Portuguese Foundation for Science and Technology (FCT; grant number PTDC/DTP-PIC/0747/2012). A. R. Gaio and O. Felgueiras were partially supported by CMUP (UID/MAT/ 00144/2013), which is funded by FCT with national (MEC) and European structural funds (FEDER), under the partnership agreement PT2020. Funding information for this article has been deposited with Open Funder Registry.

Conflict of interest: Disclosures can be found alongside this article at erj.ersjournals.com

Acknowledgements: The author's contributions are as follows. Conception and design: R. Duarte and O. Oliveira; analysis and interpretation: J. Francisco, O. Felgueiras, A.R. Gaio and R. Duarte; drafting the manuscript for important intellectual content: J. Francisco, O. Oliveira, A.R. Gaio and R. Duarte. 
TABLE 1 Statistical description and multivariate analysis

\begin{tabular}{|c|c|c|c|c|c|c|c|c|c|c|c|c|}
\hline & \multicolumn{6}{|c|}{ Males } & \multicolumn{6}{|c|}{ Females } \\
\hline & \multirow[t]{2}{*}{ TB } & \multirow[t]{2}{*}{ No TB } & \multirow[t]{2}{*}{ p-value } & \multicolumn{3}{|c|}{ Multivariate analysis } & \multirow[t]{2}{*}{ TB } & \multirow[t]{2}{*}{ No TB } & \multirow[t]{2}{*}{ p-value } & \multicolumn{3}{|c|}{ Multivariate analysis } \\
\hline & & & & Estimated OR & $\begin{array}{l}95 \% \mathrm{Cl} \text { for the } \\
\text { estimated } \mathrm{OR}\end{array}$ & p-value & & & & Estimated OR & $\begin{array}{l}95 \% \mathrm{Cl} \text { for the } \\
\text { estimated } \mathrm{OR}\end{array}$ & p-value \\
\hline Subjects $n$ & 86 & 60 & & & & & 44 & 90 & & & & \\
\hline Age years & $48.1 \pm 17.0$ & $56.8 \pm 15.7$ & 0.003 & 0.962 & $0.938-0.988$ & 0.004 & $40.8 \pm 15.6$ & $55.4 \pm 15.9$ & $<0.001$ & 0.949 & $0.925-0.974$ & $<0.001$ \\
\hline Unemployment & $25(29)$ & $7(12)$ & 0.015 & 2.374 & $0.902-6.247$ & 0.080 & $14(32)$ & $18(18)$ & 0.074 & & & \\
\hline \multicolumn{13}{|l|}{ Drug abuse } \\
\hline No & $78(91)$ & $58(97)$ & 0.336 & & & & & & & & & \\
\hline Yes & $6(7)$ & $2(3)$ & ๆ & & & & $1(2)$ & $0(0)$ & + & & & \\
\hline Imprisonment & $1(1)$ & $0(0)$ & + & & & & $1(1)$ & $0(0)$ & + & & & \\
\hline Homelessness & $1(1)$ & $0(0)$ & + & & & & $1(1)$ & $0(0)$ & + & & & \\
\hline Community shelter & $1(1)$ & $0(0)$ & + & & & & $1(1)$ & $0(0)$ & + & & & \\
\hline \multicolumn{13}{|l|}{ Current smoking } \\
\hline No consumption" & $23(27)$ & $29(48)$ & ๆ & & & & $30(68)$ & $89(63)$ & ๆ & & & \\
\hline Previous consumption & $16(18)$ & $16(27)$ & 0.701 & & & & & & & & & \\
\hline Current consumption & $47(55)$ & $14(23)$ & $<0.001$ & & & & $14(32)$ & $10(11)$ & 0.002 & 2.523 & $0.947-6.724$ & 0.064 \\
\hline \multicolumn{13}{|l|}{ Co-morbidities } \\
\hline Diabetes mellitus & $3(3)$ & $31(52)$ & $<0.001^{\S}$ & & & & $6(14)$ & $46(46)$ & $<0.001^{\S}$ & & & \\
\hline Cancer & $1(1)$ & $1(2)$ & + & & & & $1(2)$ & $1(1)$ & + & & & \\
\hline Silicosis & $0(0)$ & $0(0)$ & + & & & & $1(2)$ & $0(0)$ & + & & & \\
\hline \multicolumn{13}{|l|}{ Alcohol consumption } \\
\hline No & $35(41)$ & $28(47)$ & ๆ & & & & $39(89)$ & $74(75)$ & ๆ & & & \\
\hline Yes & & & & & & & $5(11)$ & $25(25)$ & 0.067 & & & \\
\hline $0-38 \mathrm{~g} \cdot \mathrm{day}^{-1}$ & $20(23)$ & $22(37)$ & 0.426 & 1.847 & $0.679-5.027$ & 0.230 & & & & & & \\
\hline$\geqslant 38 \mathrm{~g} \cdot$ day $^{-1}$ & $31(38)$ & $10(17)$ & 0.041 & 4.024 & $1.508-10.738$ & 0.005 & & & & & & \\
\hline
\end{tabular}




\section{References}

1 Diel R, Loddenkemper R, Zellweger JP, et al. Old ideas to innovate tuberculosis control: preventive treatment to achieve elimination. Eur Respir J 2013; 42: 785-801.

2 Flynn JL, Bloom BR. Role of T1 and T2 cytokines in the response to mycobacterium tuberculosis. Ann N Y Acad Sci 1996; 795: 137-146.

3 Rush B. An inquiry into the effects of ardent spirits upon the human body and mind: With an account of the means of preventing and of the remedies for curing them. 8th Edn. James Loring, Boston, 1785.

4 Szabo G, et al. Alcohol and susceptibility to tuberculosis. Alcohol Health Res World 1997; 21: 39-41.

5 Lönnroth K, Migliori GB, Abubakar I, et al. Towards tuberculosis elimination: an action framework for low-incidence countries. Eur Respir J 2015; 45: 928-952.

6 D'Ambrosio L, et al. Tuberculosis elimination: theory and practice in Europe. Eur Respir J 2014; 43: 1410-1420.

7 Thomasson HR. Gender differences in alcohol metabolism. Physiological responses to ethanol. Recent Dev Alcohol. 1995; 12: 163-179.

8 Lönnroth K, Williams BG, Stadlin S, et al. Alcohol use as a risk factor for tuberculosis - a systematic review. BMC Public Health 2008; 8: 289.

9 World Health Organization. Tuberculosis. Available from www.who.int/mediacentre/factsheets/fs104/en/ Date last accessed: May, 2016. Date last updated: March, 2016.

10 Przybylski G, Dabrowska A, Pilaczyńska-Cemel M, et al. Unemployment in TB patients: ten-year observation at regional center of pulmonology in Bydgoszcz, Poland. Med Sci Monit 2014; 20: 2125-2131.

11 Ploubidis GB, Palmer MJ, Blackmore C, et al. Social determinants of tuberculosis in Europe: a prospective ecological study. Eur Respir J 2012; 40: 925-930.

12 de Colombani P, Hovhannesyan A. Social determinants and risk factors for tuberculosis in national surveillance systems in Europe. Public Health Action 2015; 5: 194-201.

13 Creswell J, Raviglione M, Ottmani S, et al. Tuberculosis and noncommunicable diseases: neglected links and missed opportunities. Eur Respir J 2011; 37: 1269-1282.

14 Getahun H, Matteelli A, Abubakar I, et al. Management of latent Mycobacterium tuberculosis infection: WHO guidelines for low tuberculosis burden countries. Eur Respir J 2015; 46: 1563-1576. 